\title{
Higher well-being with similar partner? Testing the similarity hypothesis for socio-demographic characteristics
}

\author{
Ellen Verbakel \\ Department of Sociology \\ Radboud University \\ P.O. Box 9104 \\ 6500 HE Nijmegen \\ The Netherlands
}

E.Verbakel@ru.nl

\author{
Christiaan Monden \\ Nuffield College / Department of Sociology \\ University of Oxford \\ Manor Road Building \\ Manor Road \\ Oxford, OX13UQ \\ United Kingdom \\ christiaan.monden@nuffield.ox.ac.uk
}

\begin{abstract}
Studies on marriage and divorce often assume, explicitly or implicitly, that there is a positive relationship between partner similarity and well-being. We test this similarity hypothesis: do individuals who share more socio-demographic characteristics with their partners report higher well-being than individuals whose partners are less similar? We analyzed information on more than 2,300 married and cohabiting couples aged 18-50 from the UK Understanding Society wave 1 survey. Three dimensions of well-being were assessed: relationship quality, life satisfaction and psychological distress. We examined similarity on seven characteristics separately and as an index of similarity: age, father's class, education, ethnicity, religiosity, native language, and parental divorce. The results provided no support for the similarity hypothesis: there was no evidence for a positive association between partner similarity and the three well-being measures. We discuss the implications of this finding for our understanding of partner choice and divorce.
\end{abstract}

\section{Acknowledgements}

Understanding Society is an initiative by the Economic and Social Research Council, with scientific leadership by the Institute for Social and Economic Research, University of Essex, and survey delivery by the National Centre for Social Research. 


\section{Introduction}

It has been well-documented that the proverb "Birds of a feather flock together" applies to marriage patterns in many societies across time (Kalmijn 1998; McPherson, SmithLovin, and Cook 2001; Smits and Park 2009). Romantic partners, whether dating, cohabiting or married, show a strong tendency to resemble each other on major sociodemographic characteristics, such as age, ethnicity, religion, education and social class origin (e.g. Kalmijn and van Tubergen 2010; Rosenfeld 2008; Smits, Ultee, and Lammers 1998). Another proverb often applied to relationships - "Opposites attract" - has received hardly any empirical support, at least not with regard to major socio-demographic characteristics. To the contrary, socio-demographic differences between partners seem to attract divorce (Bratter and King 2008; Hohmann-Marriott and Amato 2008; Janssen 2002; Milewski and Kulu 2014; Smith, Maas, and van Tubergen 2012; Zhang and Van Hook 2009).

One widely held explanation for partner similarity in couples is a universal preference for sharing the same social characteristics with one's partner (Kalmijn 1998). This preference explanation suggests that being similar to one's partner brings something positive, and indeed many studies in the sociological and demographic literatures on partnership formation, marriage, and divorce assume a positive association between partner similarity and well-being. In contrast to psychological studies (Dyrenforth et al. 2010; Finkel et al. 2012; Luo and Klohnen 2005; Montoya, Horton, and Kirchner 2008), where the similarity in personality and attitudes is explicitly hypothesized to increase relationship well-being, the similarity hypothesis has mostly been implicit when it concerns socio-demographic characteristics. There are only few examples where the similarity presumption was stated and tested explicitly (see for instance Milewski and Kulu 2014). We focus on socio-demographic characteristics that are stable in adult life and have been known to play important roles in partnership formation. Our first contribution is to make the assumption of positive well-being effects explicit and formulate a general and testable similarity hypothesis for socio-demographic characteristics: people with partners who are similar to themselves report higher levels of well-being than people with dissimilar partners. Second, we provide a comprehensive test of the similarity hypothesis based on data from a large nationally representative sample from the UK. Our test includes seven socio-demographic characteristics - age, father's class, education, ethnicity, religiosity, native language, and parental divorce and three different well-being outcomes - relationship quality, life satisfaction, and psychological distress. These socio-demographic characteristics are common in the literature on marriage and divorce and can be characterized as rather stable in adult life. The inclusion of three outcome measures prevents our conclusions from being driven by the choice for a particular dimension of well-being. Finally, we also consider similarity on several dimensions simultaneously rather than focusing on similarity on isolated characteristics only. 
Below we outline how the similarity hypothesis has been part of the sociological and demographic literature. Building on these research traditions we formulate our general similarity hypothesis. We then set out our research design and present our results. We end by discussing the theoretical implications of our findings and how to reconcile our findings with the observations that dissimilar couples are more likely to divorce.

\section{The similarity hypothesis}

The similarity hypothesis - partner similarity is positively associated with well-being can be found in sociological and demographic studies on interpersonal attractiveness and assortative mating on the one hand, and in studies on divorce and relationship satisfaction on the other hand.

Most studies on assortative mating assume that people have a general preference for a socio-demographically similar partner (Kalmijn 1998; Schwartz 2013). Similarity increases mutual understanding; shared knowledge and values would facilitate communication and joint activities and reduce conflict (Kalmijn 1998). Third parties such as family and friends are also assumed to support the choice for similarity because in-group partners help to retain internal cohesion and homogeneity of the group (Kalmijn 1998). An alternative explanation for assortative mating is that not matching but competition drives partnership formation. If everybody prefers a partner with 'more of the characteristic' (e.g., more education), most people will partner with someone rather similar (Schwartz 2013; Hitsch, Hortaçsu, and Ariely 2010). Most evidence, including studies on online dating behavior, supports the matching principle on socio-demographic characteristics (Schwartz 2013; Hitsch, Hortaçsu, and Ariely 2010). The implications of similarity for well-being are both direct and indirect: more similarity would increase wellbeing directly through partner interaction, and indirectly through higher social support and approval from others.

Also in research on gender roles in households we find the notion of positive effects of similarity. Simpson and England (1981), for instance, formulated it like this: "The notion that shared world views enhance solidarity is compatible with the theory of homogamous mate selection, as well as with research showing that communication is the social-psychological variable that best predicts marital satisfaction". Also Becker, who argued that dissimilarity on characteristics that are substitutes (productivity characteristics) would increase the gains to marriages, stated that for complementary characteristics (such as religion, race) marital stability and happiness would benefit from similarity (Becker 1974; Becker, Landes, and Michael 1977). Note that Becker's idea that partners benefit from dissimilarity in productivity characteristics has been contested. In modern society, specialization is not in the best interest of both partners (especially of women) because the risks of economic independence are too high in light of increased divorce risks (Oppenheimer 1997). Modern marriage is therefore argued to be more about joint consumption than about joint production (Stevenson and Wolfers 2008). The emphasis on joint consumption implies - in line with the similarity hypothesis - that the 
gains of marriage are larger when partners can share ideas and hobbies, which is most likely when partners share socio-demographic characteristics.

Whereas the similarity hypothesis is often implicit in the assortative marriage literature, the divorce literature is rather explicit: one can find many explicit hypotheses stating that dissimilarity increases the risk of union dissolution (Hohmann-Marriott and Amato 2008; Jalovaara 2003; Janssen 2002; Milewski and Kulu 2014; Zhang and Van Hook 2009). Smith and colleagues (2012) refer to the idea that there are preferences for similar partners and social pressure for similarity as "homogamy theory". They argue that similarity will increase relationship quality and decrease divorce chances. Zhang and Van Hook (2009) refer to "homogamy perspective" for this same idea. Both studies concern divorce and ethnically mixed marriages, but the argument can be generalized to other characteristics. Increased divorce risks have been found when partners are different from each other with regard to several characteristics: ethnicity or immigrant status (Bratter and King 2008; Dribe and Lundh 2012), age (Clarkwes, 2007; Tzeng 1992), education (Clarkwest 2007; Tzeng 1992), church attendance (Lehrer and Chiswick 1993), and health (Wilson and Waddoups 2002).

Variants of the similarity hypothesis can be found in studies on relationship quality and relationship satisfaction, which are often psychologically oriented. In those studies, scholars have been primarily interested in partner similarity in personality (e.g., Luo and Klohnen 2005), values and attitudes (e.g., Keizer and Komter 2015) and other socio-psychological characteristics (e.g. Montoya, Horton, and Kirchner 2008) rather than socio-demographic characteristics. There is some support for the idea that matching on personality is beneficial (Luo and Klohnen 2005), but support for similarity in attitudes and values is more mixed (Keizer and Komter 2015). Note that attitudes and values likely change across adult life and with important life course transitions, while our set of sociodemographic characteristics is mostly fixed by the time of partnership formation.

We take into account that dissimilarity on one characteristic may not lower wellbeing when it is compensated by similarity on another, possible more important, characteristic. For example, a large age difference may be non-problematic if it enables somebody to marry within a small local ethnic or religious group. The existence of such trade-offs means that even if most people generally prefer similarity, there will be people with a dissimilar partner on certain characteristics who will not experience a negative effect. If 'non-problematic dissimilarities' are distributed over all kinds of characteristics, the likelihood of finding a strong, positive similarity effect for any particular characteristic is reduced. This line of thought suggests we should consider multiple characteristics simultaneously, and therefore we will also construct a similarity index that captures the extent of partner similarity regardless of which specific characteristic(s) partners are similar on. 


\section{Data and methods}

\subsection{Data}

We used data from the first wave of Understanding Society, a nationally representative social science household survey for the UK (for detailed documentation see: www.understandingsociety.ac.uk) (University of Essex 2012). The first wave of data was collected in face-to-face interviews between January 2009 and December 2011 among all members aged 16 and older in 39,802 households. Individual response rates in wave one varied from $72.4 \%$ in the ethnic minority sub-sample to $77.3 \%$ and $82.0 \%$ in the general household samples for Great Britain and Northern Ireland respectively.

Understanding Society is highly suitable for our purpose for three reasons. First, Understanding Society contains dyadic information as both partners in a couple reported on their own well-being and socio-demographic characteristics. Second, Understanding Society contained good measurements of relationship quality and general well-being. Third, Understanding Society had a large sample size that allowed us to capture relatively small effects and that ensured that we had sufficient observations of couples with infrequent combinations of characteristics.

\subsection{Case selection}

We selected married and cohabiting couples where both partners were aged between 18 and 50; this reduced the number of couples from $n=11,296$ to $n=5,891$. We further restricted relationship duration to 10 years $(n=3,221)$ in order to minimize underrepresentation of dissimilar couples, who were more prone to divorce (we performed robustness checks in which we varied restrictions on relationship duration). Because we wanted equal samples for our three outcomes, we used simple list wise deletion of missing cases. The final analytical sample consisted of 2,377 couples.

\subsection{Variables and measurements}

\subsubsection{Dependent variables}

We examined three dimensions of well-being: relationship quality, life satisfaction, and psychological distress.

Relationship quality was measured with eight items. Respondents were asked to report on a scale of 1 to 6 the frequency of the interactions with their partner: (a) Have a stimulating exchange of ideas; (b) Calmly discuss something; (c) Work together on a project. Answer categories for items (a)-(c) were: (1) never; (2) less than once a month, (3) once or twice a month, (4) once or twice a week, (5) once a day, (6) more often. The other five items were: (d) How often do you discuss or have you considered divorce, separation or terminating your relationship?; (e) Do you ever regret that you married or lived together?; (f) How often do you and your partner quarrel?; (g) How often do you and your partner get on each other's nerves?; and (h) How often do you kiss your partner? Answer categories for (d)-(g) were: (1) all the time; (2) most of the time; (3) more often than not; (4) occasionally; (5) rarely; (6) never. Cronbach's alpha was high: 0.79 and 0.81 
for men and women respectively. Factor analysis confirmed that the items form a single scale (i.e., they all loaded highly on the same factor and only one factor had an Eigenvalue higher than 1). We reversed the score for item (h) and took the average of the 8 items for a score between 1 and 6 that reflects relationship quality. Average levels of relationship quality did not differ by gender ( 4.87 for men and 4.86 for women), but husbands and wives apparently experienced relationship quality in slightly different ways; the correlation between husbands' and wives' reported relationship quality was positive but perhaps not as high one might expect: $r=0.56$.

Life satisfaction was measured with a single item question: "Please tick the number which you feel best describes how dissatisfied or satisfied you are with the following aspects of your current situation: Your life overall." Answer categories ran from 1 to 7: (1) completely dissatisfied; (2) mostly dissatisfied; (3) somewhat dissatisfied; (4) neither satisfied nor dissatisfied; (5) somewhat satisfied; (6) mostly satisfied; (7) completely satisfied. Women reported somewhat higher levels of life satisfaction (5.40) than men (5.24). The correlation between husbands' and wives' life satisfaction was $r=$ 0.26 .

Finally, psychological distress was measured with the General Health Questionnaire (GHQ). The GHQ-12 was originally developed as a screening instrument for psychiatric illness (Goldberg et al. 1997) and is frequently used as a general measure of psychological distress (Thomas, Benzeval, and Stansfeld 2005). Respondents were asked "Have you recently..." (a) ...been able to concentrate on whatever you're doing; (b) ... lost much sleep over worry; (c) ...felt that you were playing a useful role in things; (d) ...felt capable of making decisions about things; (e) ...felt constantly under strain; (f) ... felt you couldn't overcome your difficulties; (g) ... been able to enjoy your normal day-to-day activities; (h) ... been able to face up to problems; (i) ...been feeling unhappy or depressed; (j) ... been losing confidence in yourself; (k) ...been thinking of yourself as a worthless person; (1) ... been feeling reasonably happy all things considered. Answer categories were: (0) not at all; (1) no more than usual; (2) rather more than usual; (3) much more than usual. Positive items were reversed in such a way that high scores mean high levels of psychological distress, and hence lower mental well-being. After summing the items the scores ranged from 0 to 36 with men scoring on average 10.48 and women 11.08. Again, husbands' and wives' psychological distress was positively correlated, but only moderately so: $r=0.25$.

Figure 1 presents the distribution of the three outcome variables by sex. Among men the life satisfaction had the strongest correlation with psychological distress, namely $r=-0.51$. Relationship quality was correlated less strongly with life satisfaction and psychological distress; $r=0.29$ and $r=-0.25$ respectively. For women, similar correlations among the three dependent variables were observed, $r=-0.48, r=0.29$ and $r=-0.27$, respectively. 

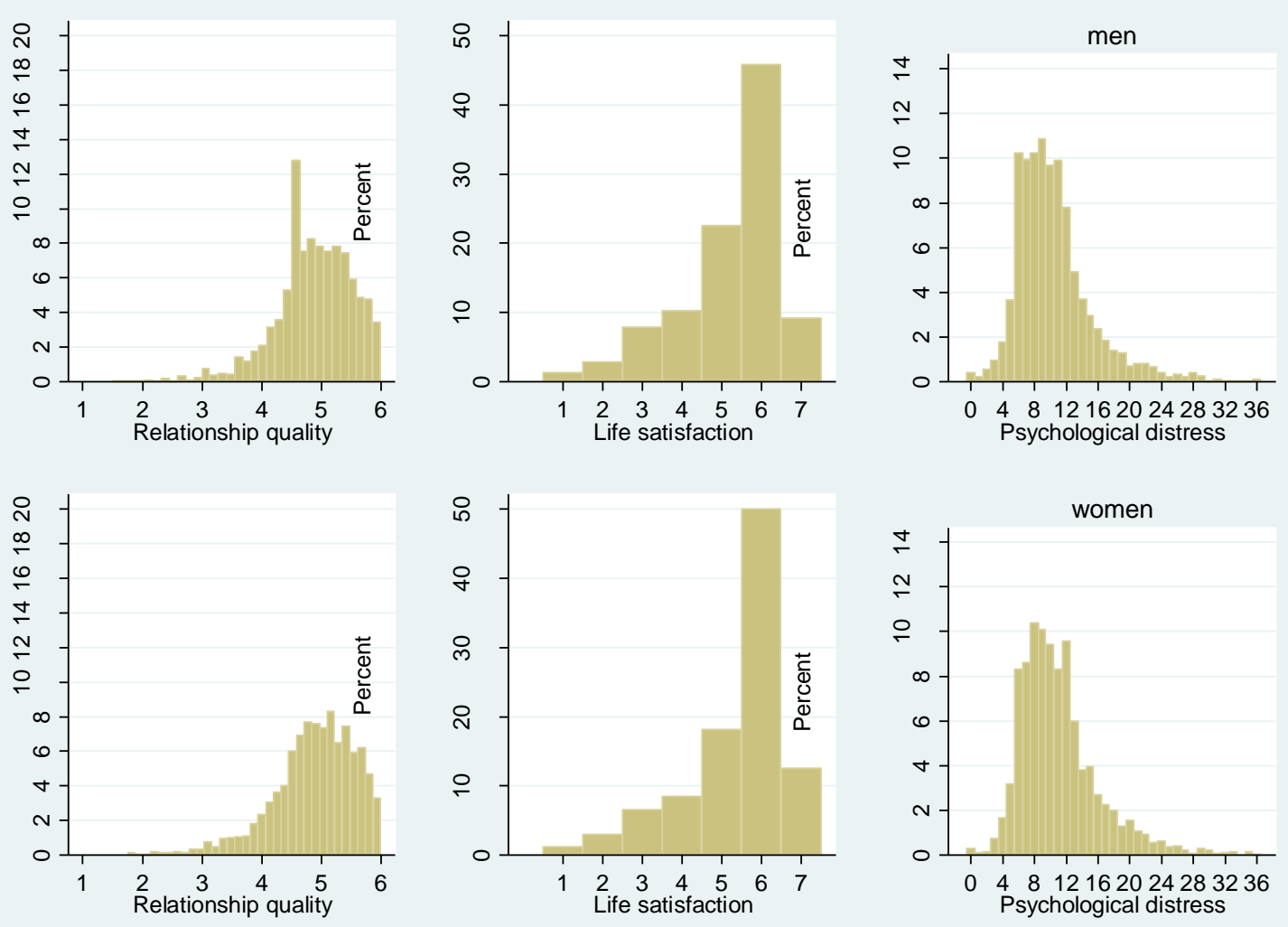

Figure 1. Distribution of the three dependent well-being variables by sex

\subsubsection{Characteristics for partner similarity}

We considered similarity on seven characteristics: age, father's social class, educational attainment, ethnicity, religiosity, native language and parental divorce. We limited this list to characteristics that are generally stable during the relationship. Similarity therefore referred to the partner selection process rather than to convergence during the relationship (e.g., as a result of mutual influence or shared exposures).

Age. In the UK, as in most Western societies, the husband is usually slightly older than his wife. An age differences of 0,1 or 2 years is the most common pattern in the total sample of Understanding Society. We distinguished five levels of age-differences between husbands and wives: (1) husband was more than 5 years younger; (2) husband was 2 to 5 years younger; (3) husband was one year younger to three years older; (4) husband was 4 to 9 years older; (5) husband was 10 or more years older. These cut-off points are obviously largely arbitrary and were therefore subjected to a sensitivity analysis (see section 4.4). About half (51\%) of the couples in our analytic sample had a 'standard' age-difference, that is, the husband was between one year younger and three years older than the wife.

Father's class refers to father's occupational class when the respondent was aged 14. It was measured with the National Statistics Socio-economic Classification (NS-SEC) which distinguishes (1) managerial and professional occupations; (2) intermediate 
occupations; (3) small employers and own account workers; (4) lower supervisory and technical occupations; (5) semi-routine and routine occupations. A non-trivial number of respondent (16.5\%) had no valid score on father's occupational class, most likely because the father was either non-employed or absent when the respondent was 14 years old. We included this category in the analysis. We defined a couple as similar if both fathers fell in the same occupational class - two missing occupations did not count as similarity. Almost one in three (31\%) couples had a similar social origin (excluding couples where the occupation of the one the fathers is unknown).

Educational attainment was coded in four categories: (1) a tertiary degree; (2) Alevel qualifications or equivalent (these corresponds to higher secondary education); (3) GCSE qualification or equivalent (finished secondary school to age 16); (4) lower levels. These levels roughly correspond to ES-ISCED-levels 5, 3a/4, 2 and 1, respectively. Similarity was simply defined as both partners having educational qualification of an equivalent level. Almost half of the couples (48\%) in our analytic sample had similar levels of education.

Ethnicity was measured by self-report: “What is your ethnic group?". Despite the large sample size, the numbers of mixed marriages were rather small and we therefore combined several ethnic groups into a five-category scheme: 'White British' was by far the largest group and contained English, Scottish, Welsh, and Northern Irish; 'Other white' included among others Irish; 'Asian' included Indian, Pakistani, Bangladeshi, Chinese and people with any other Asian background; 'Black' included Caribbean and African background and people from any other black background; 'Other' was a highly mixed group including Arab, mixed ethnicities (for example white and black African), and any other non-mentioned ethnic group. When we compared levels of well-being in the cross-table of husband's by wife's ethnicity we only considered White British, Asian and Black because the other combinations (i.e., Other white, Asian and Other) had too few observations. When we compared similar to non-similar couples all ethnic groups were included. Couples where both partner's reported their ethnicity as "other" were excluded. Only $5 \%$ of the couples were ethnically mixed in our definition.

English as native language. As language is highly important for communication in general and between partners in a couple, we included whether both partners share English as their native language. $91.5 \%$ of the couples were similar in the sense that either both $(81.9 \%)$ or neither partner $(9.6 \%)$ had English as their native language.

Religiosity. Respondents were first asked whether they regarded themselves as belonging to any particular religion. Those who did not regard themselves as such were asked whether they were brought up in any particular religion. Note that those who reported belonging to a particular religion were assumed to have been brought up in that religion (this seems a fair assumption; see for instance Bruce 2002). On the basis of current belonging and upbringing we distinguished three categories: (1) Not raised religiously, not belonging to a religion now; (2) Religious upbringing, but no longer religious; (3) Religious upbringing and still religious. Just over half (56\%) of the couples in our analytic sample were similar with regard to religious socialization. Note that with 
respect to current religiosity, we could not rule out the impact of converging processes during the relationship.

Parental divorce. Finally, we distinguished couples where the partners had similar experience with regard to parental divorce before the age of 16 . In three out of four couples $(74 \%)$, both husband and wife had the same experience. In only $5 \%$ of couples both partners experienced a parental divorce before they were 16 .

Appendix 1 gives the number of couples by husband's and wife's characteristics.

\subsubsection{Control variables}

We controlled for a set of five factors in all models. First, we controlled for the respondents' own age and age squared. Second, we controlled for marital status (married versus cohabiting). The literature on marital status and well-being has shown that married individuals are happier than cohabiting individuals (Soons and Kalmijn 2009; Verbakel 2012). Cohabiting couples are more heterogeneous than married couples and they may differ in other relevant ways as well. Third, we controlled for relationship duration (months since first living together/marriage). Duration could be correlated with both similarity and well-being if heterogeneous unions are more likely to dissolve and if, at the same time, longer-lasting couples are the happier unions. Finally, we controlled for the number of children living in the household and household income (logged) because these two factors are correlated with well-being and may be affected by similarity.

\subsection{Analytic strategy}

For each combination of outcome variable (i.e., relationship quality, life satisfaction, and psychological distress) and characteristic (i.e., age, father's class, education, ethnicity, religiosity, native language, and parental divorce), we tested the similarity hypothesis by fitting a series of seven models on our data (listed in the next paragraph). Our basic strategy was to first compare the model fits to assess whether models with a parameter for similarity fitted the data better than models that did not assume an effect of similarity. The similarity parameter simply assessed whether husband and wife had the same score on the particular characteristic (1) or not (0). If a model with the similarity parameter best fitted the data, we then inspected the signs and significance levels of the regression coefficients of the preferred model to find out whether the coefficients supported the similarity hypothesis (relevant coefficients will be discussed in the results section; analyses available upon request).

We specified separate regression equations for men and women in a seemingly unrelated regression model (Zellner 1962) to take account of the unobserved influences that the partners in a couple share (we used the SUREG command in STATA 13.1). Our baseline model (Model 1) included our set of controls only. Model 2 contained the dummy indicator for similarity in addition to the control variables. An improved fit of Model 2 over Model 1 implied that belonging to a similar couple matters for one's well-being. We expected the regression coefficient for similarity to be positive. Model 3 (controls + own characteristic) took into account that the particular characteristic was likely to have a 
direct effect on well-being; for instance education might be positively related to wellbeing. Model 4 (controls + own characteristic + similarity) added the similarity effect to the previous model. Next, we added the direct effect of the partner's characteristic in Model 5 (controls + own characteristic + partner's characteristic). Well-being might be associated with the partner's characteristic, net of one's own score, for example because a highly educated partner brings additional resources into the household. Model 6 added the similarity dummy to the previous model (controls + own characteristic + partner's characteristics + similarity). A model fit improvement from Model 5 to 6 implied that there were benefits associated with being similar beyond the simple additive characteristics of the two partners. This would mean, for instance, that the higher wellbeing of a college graduate with an equally educated partner could not be completely attributed to their high level of resources, but was partly associated with their similarity. The final and most complex model, Model 7, included parameters for all combinations of the individual and partner's characteristic (except for one combination that was the reference category). This model allowed for more complex effects of similarity than a simple dichotomous similarity effect (as in Models 2, 4, and 6). It could pick up asymmetric effects - couples in which the husband has the 'higher' score may differ from couples in which the wife has the 'higher' score on a particular characteristic. In addition, this model allowed for small dissimilarities to have less weight than larger dissimilarities - couples with a 2-level difference in education may differ more from similar couples than couples with a 1 - level difference in education. If Model 7 had the best fit, an inspection of the parameters determined whether the pattern supported the similarity hypothesis. Note that for the two dichotomous characteristics (native language and parental divorce) Model 6 and 7 were equivalent (both models used three parameters to describe four cells and are thus a reparameterization of each other). We assessed goodness-of-fit with the Akaike Information Criterion (AIC) .We preferred AIC over BIC because AIC penalizes the addition of extra parameters less strongly. Consequently, the addition of the similarity indicator was more likely to result in a better model fit using AIC. Thus, by using AIC we were more likely to find support for the similarity hypothesis.

In addition to testing the similarity hypothesis for each characteristic separately, we tested it by regressing the number of similar characteristics on the three well-being outcomes. Again we specified separate equations for men and women in seemingly unrelated regression models (controls included).

\section{Results}

\subsection{Testing the similarity hypothesis separately for each characteristic}

Table 1 presents the goodness-of-fit of seven models for each outcome measure and each characteristic separately; the lowest AIC values (and hence the best fitting models) are shaded in grey. 
Table 1. Goodness-of-fit (AIC) of seemingly unrelated regression models for men's and women's relationship quality, life satisfaction and psychological distress for each of the seven characteristics

\begin{tabular}{|c|c|c|c|c|c|c|c|}
\hline Relationship quality & Age & $\begin{array}{c}\text { Father's } \\
\text { class }\end{array}$ & Education & Ethnicity & Religiosity & $\begin{array}{c}\text { Native } \\
\text { language }\end{array}$ & $\begin{array}{l}\text { Parental } \\
\text { divorce }\end{array}$ \\
\hline 1. Controls & 8407.7 & 8413.9 & 8413.9 & 7162.9 & 8413.9 & 8413.9 & 8413.9 \\
\hline 2. $1+$ similarity & 8409.8 & 8416.5 & 8415.6 & 7160.9 & 8406.2 & 8413.5 & 8415.9 \\
\hline 3. Controls + own characteristic & 8413.9 & 8415.7 & 8409.3 & 7163.8 & 8274.7 & 8416.3 & 8183.2 \\
\hline 4. $3+$ similarity & 8416.2 & 8417.8 & 8410.4 & 7161.2 & 8268.6 & 8413.0 & 8185.7 \\
\hline 5. Controls + own characteristic + partner characteristic & 8416.4 & 8418.0 & 8407.7 & 7166.8 & 8277.0 & 8413.3 & 8184.1 \\
\hline $6.5+$ similarity & 8418.8 & 8420.3 & 8408.6 & 7165.2 & 8268.4 & 8411.2 & 8187.0 \\
\hline 7. Controls + all combinations of own*partner characteristic & 8423.3 & 8475.0 & 8416.8 & 7173.9 & 8275.3 & 8411.2 & 8187.0 \\
\hline \multicolumn{8}{|l|}{ Life satisfaction } \\
\hline 1. Controls & 15294.0 & 15275.6 & 15275.6 & 13059.2 & 15275.6 & 15275.6 & 15275.6 \\
\hline 2. $1+$ similarity & 15296.9 & 15275.1 & 15278.8 & 13050.1 & 15278.6 & 15260.1 & 15274.5 \\
\hline 3. Controls + own characteristic & 15275.6 & 15285.1 & 15264.0 & 13053.1 & 15032.2 & 15279.2 & 14842.5 \\
\hline 4. $3+$ similarity & 15279.4 & 15283.7 & 15265.9 & 13046.3 & 15034.8 & 15263.2 & 14844.5 \\
\hline 5. Controls + own characteristic + partner characteristic & 15281.7 & 15294.3 & 15264.5 & 13055.4 & 15033.5 & 15273.3 & 14839.8 \\
\hline $6.5+$ similarity & 15285.3 & 15291.6 & 15264.5 & 13051.2 & 15036.9 & 15263.6 & 14843.0 \\
\hline 7. Controls + all combinations of own*partner characteristic & 15286.4 & 15336.8 & 15266.4 & 13036.1 & 15044.7 & 15263.6 & 14843.0 \\
\hline \multicolumn{8}{|l|}{ Psychological distress } \\
\hline 1. Controls & 27949.8 & 27907.2 & 27907.2 & 23785.5 & 27907.2 & 27907.2 & 27907.2 \\
\hline 2. $1+$ similarity & 27950.9 & 27908.7 & 27911.2 & 23777.9 & 27908.3 & 27906.6 & 27897.0 \\
\hline 3. Controls + own characteristic & 27907.2 & 27907.2 & 27903.9 & 23776.4 & 27431.3 & 27901.9 & 27171.4 \\
\hline 4. $3+$ similarity & 27911.0 & 27909.0 & 27907.3 & 23767.2 & 27432.7 & 27892.7 & 27163.5 \\
\hline 5. Controls + own characteristic + partner characteristic & 27908.3 & 27916.3 & 27908.8 & 23782.1 & 27426.1 & 27902.7 & 27166.2 \\
\hline $6.5+$ similarity & 27909.8 & 27917.3 & 27911.4 & 23774.2 & 27429.3 & 27895.6 & 27162.5 \\
\hline 7. Controls + all combinations of own*partner characteristic & 27907.7 & 27976.1 & 27926.5 & 23773.5 & 27434.4 & 27895.6 & 27162.5 \\
\hline
\end{tabular}

Controls include age, age squared, log household income, children at home, cohabitation and relationship duration. In grey are the models with the lowest AIC value 
With respect to age, we observed that the models without similarity had a better fit than those with a similarity parameter. More precisely, for relationship quality the model with control variables only was preferable, and for life satisfaction and psychological distress the model that included own age and controls fitted the data best. Hence, with respect to age, we found no support for the similarity hypothesis.

The models for father's class gave one reason to further inspect the results. Life satisfaction was best modeled when the similarity dummy was included. However, similarity appeared to have a negative effect on life satisfaction $(b=-0.059, p=0.321$ for men; $b=-0.121, p=0.041$ for women), which obviously contradicts the similarity hypothesis.

For education, adding a similarity parameter did not improve the goodness-of-fit. The coefficients for own and partner's education - which represent the direct effects of individual and partner's characteristic - had plausible signs: higher education was associated with better outcomes.

For ethnicity, models that included similarity showed the best fit (Model 2 for relationship quality; Model 7 for life satisfaction; Model 4 for psychological distress). The regression coefficients indicated that similarity was positively associated with relationship quality $(b=0.143, p=0.032)$ and negatively related to psychological distress ( $b=-1.837, p=0.000$ ), but only for men. The results for life satisfaction did not reveal support for the similarity hypothesis. In sum, we found some support for a positive association between partner similarity in ethnicity and well-being, though only for men and only for two well-being outcomes.

Based on the goodness-of-fit comparisons in Table 1, similarity in religiosity contributed to relationship quality. The regression results revealed that the similarity effect was indeed positive for both men $(b=0.055, p=0.047)$ and women $(b=0.103, p$ $=0.000$ ). For life satisfaction and psychological distress, however, adding a similarity parameter did not improve the model fit. So, support for the similarity hypothesis was limited as far as religiosity is concerned.

For native language, models with similarity fitted better than models without similarity for all outcome measures. Further inspection of the regression results revealed, however, that for two outcome measures similarity appeared only beneficial for women and not for men. In addition, although relationship quality was particularly low - and psychological distress particularly high - if the woman was a native English speaker while the husband was not (favoring the similarity hypothesis), the other dissimilar couples (husband English, wife Other) did not differ from the similar couples (weakening the similarity claim). For life satisfaction both men and women reported higher scores if they were similar $(b=0.342, p=0.000$ and $b=0.308, p=0.001$ respectively). Hence, with respect to native language, our study found some support for the similarity hypothesis.

Finally, for parental divorce, one of the three outcome measures (psychological distress) was best modeled with the similarity parameter, namely with the full interactive model (Model 7), which in this case is equivalent to a model with the similarity parameter 
and own and partner's characteristic (Model 6). However, the coefficients for similarity were not significant. The full interactive model only was preferred over a simpler model because one of the four types of couples - those with no parental divorce - had better outcomes than the other three types of couples - the similar couple with two parental divorces, and the two dissimilar couples. Hence, no support was found for the similarity hypothesis with respect to parental divorce.

In sum, the general pattern is that the similarity hypothesis was not supported. We found some indications, especially for ethnicity, religiosity, and native language, but the association between similarity in these characteristics and well-being was neither consistent nor substantial.

\subsection{Testing the similarity hypothesis for all characteristics combined}

Does the degree of similarity matter rather than similarity on a particular characteristic? Being dissimilar on a particular characteristic may be traded-off against similarity in one or more other (and more important) characteristics. This would mask the negative impact of dissimilarity on well-being for separately analyzed characteristics. Under the similarity hypothesis we would expect a clear pattern of increasing well-being as the number of similar characteristics increases. Is there evidence of such a pattern?
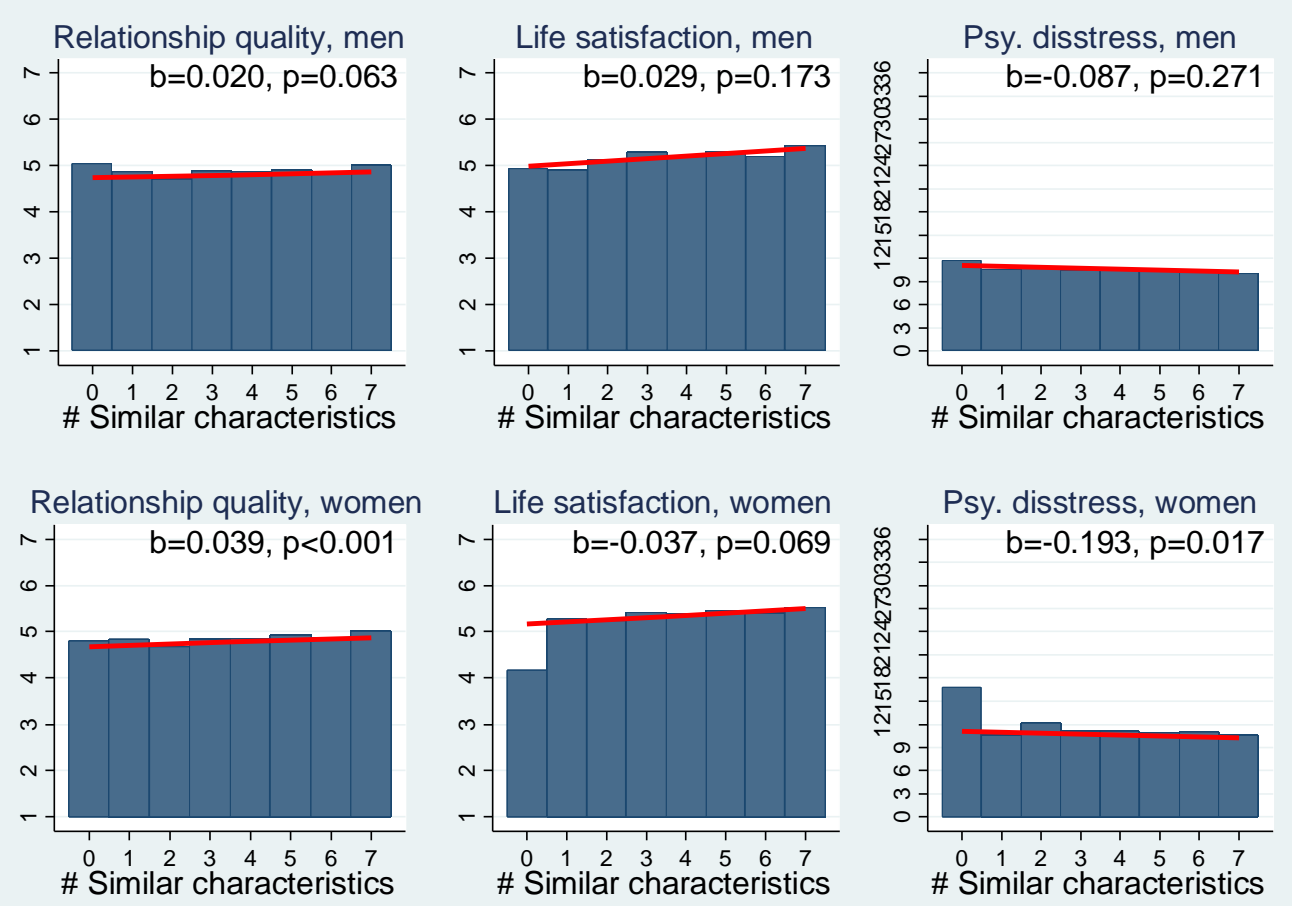

Figure 2. Adjusted means by number of similar characteristics, and linear effect of the number of similar characteristics

In Figure 2 we show adjusted well-being scores by number of similar characteristics. Four of the six estimated linear effects of the similarity index were insignificant; the 
other two were significant and indeed positive: those on relationship quality reported by women and women's psychological distress. However, the bars in the histograms show that the differences along the simple index were rather small. Also compared to the standard deviations of the dependent variables, the effect sizes were very limited. Moreover, the linear effect of dissimilarity on women's psychological distress was largely driven by few women from couples with none similar characteristics. The finding of a linear effect for relationship quality $(b=-0.039, \mathrm{p}<0.001)$ was rather robust, but it must be kept in mind that the adjusted relationship quality scores for women from couples with one, three, four or six similar characteristics were basically the same (4.83 to 4.86). Therefore, we must again conclude that this pattern did not provide convincing support for a significant, let alone substantial, effect of similarity.

\subsection{Sensitivity analysis}

We performed several additional analyses to check the robustness of our results: (i) we extended the sample selection to relationships with durations up to 20 years; (ii) we reduced the relationship duration to five years; (iii) we included older respondents (up to age 60); (iv) we dropped income from the control variables; (v) we ran separate analyses for married and cohabiting men and women. None of these additional models showed a more coherent pattern of similarity effects than any of the presented results. The lack of support for the similarity hypothesis in this data set appeared to be rather robust.

\section{Conclusion and discussion}

We used UK data to test the similarity hypothesis that states that similarity between partners is associated with higher well-being. We used a large, high quality data set that provided ample statistical power and that had good measurements for three relevant outcomes and the most important socio-demographic characteristics. As far as our set of socio-economic and demographic characteristic concerns, we found no evidence for the idea that people with more similar partners report higher relationship quality, more life satisfaction or less psychological distress than people with more dissimilar partners.

Our findings are surprising in light of the wide use and apparent acceptance of the similarity hypothesis in the social science literature. We have given the similarity hypothesis maximum chance to be supported by the analysis. First, we examined three dimensions of well-being that may be affected by partner similarity. Second, we restricted our observation window to the first ten years of the relationship. Dissimilar couples are more likely to separate and we therefore expected a stronger relationship between partner similarity and well-being in the first years of a relationship. Third, we did not include control variables that may confound the relationship between partner similarity and wellbeing, such as education, employment status, and social origin: 'success factors' that enhance the likelihood of finding a desirable (i.e., similar) partner and that contribute to well-being. Fourth, we also took into account the idea that being dissimilar in one respect does not need to harm well-being if it is compensated by similarity in other respects. Therefore, we also checked whether the similarity hypothesis received support if all 
characteristics are considered simultaneously. Finally, also methodologically we set the similarity hypothesis up for success: we compared the goodness-of-fit of models with AIC rather than BIC because AIC does not penalize larger models (i.e., more coefficients) as much as BIC does. We did not find any convincing evidence in support of the similarity hypothesis despite these choices in the setup of our analyses

So, the puzzle now is: why did we not find similarity effects on well-being, while similarity is commonly found to be associated with partner choice and divorce risks? First of all, the answer may refer to caveats in our study. Our conclusions only refer to the particular set of seven characteristics and three outcomes used in this study. However, it is particularly these characteristics that earlier studies showed to be related to partner choice and divorce risks. In addition, we would like to maintain that we actually considered a broad set of well-being outcomes: from general mental health (psychological distress) and a subjective evaluation of life (life satisfaction) to a dimension closely related to the partnership formation and dissolution process (relationship quality). Another caveat could be that we did not distinguish different types of couples, while the positive relationship between partner similarity and well-being might hold only for certain types. For instance, it could be argued that the similarity hypothesis holds especially for conformist couples, who find it important to comply to norms set by their family and social group. Matching on socio-demographic characteristics is such a norm. Meeting this norm will have positive well-being effects for conformist people. For nonconformist individuals being similar or dissimilar to one's partner would be less strongly related to well-being. Although such a pattern would weaken the relationship between similarity and well-being in our study, it does not seem plausible that such an argument drives our null-results. To completely off-set the positive similarity effects in one set of couples, there would have to be a negative effect in the alternative set of couples. It seems unlikely that similarity will be negatively related to well-being in non-conformist couples (or other subsets of couples). Finally, it must be kept in mind that our conclusions concern the UK and cannot necessarily be generalized to other countries. Countries vary to some extent in their marriage markets and cultural outlook, which may condition the importance of partner similarity. For instance, not meeting the norm of partner similarity may reduce well-being especially in familialistic societies or societies with traditional attitudes about marriage (Verbakel 2012). However, we do not see fundamental differences between the UK and other modern Western countries that would explain why the similarity effect would not apply to the UK context.

Which substantial interpretations can be put forward for the supposed inconsistency between the importance of similarity for relationship formation and dissolution on the one hand and the lack of association between similarity and well-being on the other hand? One suggestion is that, although relationship quality and divorce risks seem logically negatively related, this association is certainly not perfect. In case of a low-quality relationship, it can be argued that it is particularly similar couples that stay together. Third parties exert pressure to retain their relationship precisely because its homogamous nature is valuable to the community. Conversely, it could be argued that it 
will be particularly dissimilar couples that break up in case of a low-quality relationship; dissimilar couple may lack support from their environment or even experience pressure to end the relationship. As a result, we argue that our results challenge the assumption that dissimilarity leads to divorce via relationship quality or well-being. This assumption therefore needs more and better empirical evidence.

With respect to assortative mating and well-being, we argue that the often presumed relationship may not be as direct as it seems. The preference for a similar partner is likely to be connected to the expectation that a similar partner is the best chance for finding happiness. However, expectations do not always materialize. And, according to our study, this is also the case with respect to the expected link between similarity and well-being. This argumentation has no direct empirical implications for the assortative mating literature. Individuals' expectation that similarity will bring them happiness can still be a driving mechanism in the partner selection process. Rational actors base their actions on the knowledge they have; in this case, they may be ill-informed, but this does not change the outcome. For industries, like the online dating industry, in which the main matching principle of dating agencies appears to be similarity (Finkel et al. 2012), our findings suggest that this principle may indeed lead to (short-term) matches, but may not yield as many happy couples as one might expect.

We would like to encourage replications of tests of the similarity hypothesis. Replications for other countries can reveal to what extent our conclusion can be generalized to other Western countries. We would also like to encourage replications with different outcomes and other characteristics. Considering that the strongest results in favor of the similarity hypothesis appeared for religiosity, native language and ethnicity, future research may want to elaborate on the speculation that similarity with regard to socio-cultural characteristics matters most. 


\section{References}

Becker, Gary S. (1974). "A theory of marriage". In: Theodore W. Schultz (Ed.), Economics of the family: Marriage, children, and human capital (pp. 299-344). Chicago: The University of Chicago Press.

Becker, Gary S., Landes, Elisabeth M., and Michael, Robert T. (1977). "An economic analysis of marital instability”. Journal of Political Economy 85(6):1141-1187. doi: $10.1086 / 260631$

Bratter, Jenifer L. and King, Rosalind B. (2008). ““'But will it last?”: Marital instability among interracial and same-race couples”. Family Relations 57(2):160-171. doi: 10.1111/j.1741-3729.2008.00491.x

Bruce, Steve. (2002). God is dead: secularization in the West. Oxford: Blackwell.

Clarkwest, Andrew (2007). "Spousal dissimilarity, race, and marital dissolution". Journal of Marriage and Family 69(3):639-653. doi: 10.1111/j.1741-3737.2007.00397.x

Dribe, Martin and Lundh, Christer. (2012). "Intermarriage, value context and union dissolution: Sweden 1990-2005". European Journal of Population-Revue 28(2):139-158. doi: 10.1007/s10680-011-9253-y

Dyrenforth, Portia S., Kashy, Deborah A., Donnellan, M. Brent, and Lucas, Richard E. (2010). "Predicting relationship and life satisfaction from personality in nationally representative samples from three countries: The relative importance of actor, partner, and similarity effects". Journal of Personality and Social Psychology 99(4):690-702. doi:10.1037/a0020385

Finkel, Eli J., Eastwick, Paul W., Karney, Benjamin R., Reis, Harry T., and Sprecher, Susan. (2012). "Online dating: A critical analysis from the perspective of psychological science”. Psychological Science in the Public Interest 13(1):3-66. doi: $10.1177 / 1529100612436522$

Goldberg, David P., Gater, R., Sartorius, N., Ustun, T. B., Piccinelli, M., Gureje, O., and Rutter, C. (1997). "The validity of two versions of the GHQ in the WHO study of mental illness in general health care". Psychological Medicine 27(1):191-197. doi: $10.1017 /$ S0033291796004242

Hitsch, Günter. J., Hortaçsu, Ali, and Ariely, Dan. (2010). "Matching and sorting in online dating". American Economic Review 100(1):130-163. doi:10.1257/aer.100.1.130

Hohmann-Marriott, Bryndl E. and Amato, Paul. (2008). "Relationship quality in interethnic marriages and cohabitations". Social Forces 87(2):825-855. doi: 10.1353/sof.0.0151

Jalovaara, Marika. (2003). "The joint effects of marriage partners' socioeconomic positions on the risk of divorce". Demography 40(1):67-81. doi: 10.1353/dem.2003.0004

Janssen, Jacques P. G. (2002). Do oppposites attract divorce? Dimensions of mixed marriage and the risk of divorce in the Netherlands. Amsterdam: Thela. 
Kalmijn, Matthijs. (1998). "Intermarriage and homogamy: Causes, patterns, trends". Annual Review of Sociology 24:395-421. doi:10.1146/annurev.soc.24.1.395

Kalmijn, Matthijs and Van Tubergen, Frank. (2010). "A comparative perspective on intermarriage: explaining differences among national-origin groups in the United States". Demography 47(2):459-479. doi: 10.1353/dem.0.0103

Keizer, Renkse and Komter Aafke. (2015). "Are "equals" happier than "less equals"? A couple analysis of similarity and well-being". Journal of Marriage and Family 77(4):954-967. doi: 10.1111/jomf.12194

Lehrer, Evelyn L. and Chiswick, Carmel U. (1993). "Religion as a determinant of marital stability". Demography 30(3):385-404. doi: 10.2307/2061647

Luo, Shanhong and Klohnen, Eva C. (2005). "Assortative mating and marital quality in newlyweds: A couple-centered approach". Journal of Personality and Social Psychology 88(2):304-326. doi: 10.1037/0022-3514.88.2.304

McPherson, Miller, Smith-Lovin, Lynn, and Cook, James M. (2001). "Birds of a feather: Homophily in social networks". Annual Review of Sociology 27(1):415-44. doi: 10.1146/annurev.soc.27.1.415

Milewski, Nadja and Kulu, Hill. (2014). "Mixed marriages in Germany: A high risk of divorce for immigrant-native couples". European Journal of Population 30(1):89113. doi: 10.1007/s10680-013-9298-1

Montoya, R. Matthew, Horton, Robert S., and Kirchner, Jeffrey. (2008). "Is actual similarity necessary for attraction? A meta-analysis of actual and perceived similarity”. Journal of Social and Personal Relationships 25(6):889-922. doi: 10.1177/0265407508096700

Oppenheimer, Valerie C. (1997). "Women's employment and the gain to marriage: The specialization and trading model”. Annual Review of Sociology 23:431-53. doi: 10.1146/annurev.soc.23.1.431

Rosenfeld, Michael J. (2008). "Racial, Educational and Religious Endogamy in the United States: A Comparative Historical Perspective”. Social Forces 87(1):1-31. doi: 10.1353/sof.0.0077

Schwartz, Christine R. (2013). "Trends and variation in assortative mating: Causes and consequences”. Annual Review of Sociology 39:451-470. doi: 10.1146/annurev-soc071312-145544

Simpson, Ida H. and England, Paula. (1981). "Conjugal work roles and marital solidarity”. Journal of Family Issues 2(2):180-204. doi: 10.1177/0192513X8100200205

Smith, Sanne, Maas, Ineke, and Van Tubergen, F. (2012). "Irreconcilable differences? Ethnic intermarriage and divorce in the Netherlands, 1995-2008". Social Science Research 41(5): 1126-1137. doi: 10.1016/j.ssresearch.2012.02.004

Smits, Jeroen, Park Hyunjoon. (2009). "Five Decades of Educational Assortative Mating in 10 East

Asian Societies”. Social Forces 88(1):227-255. doi: 10.1353/sof.0.0241 
Smits, Jeroen, Ultee, Wout, and Lammers, Jan. (1998). "Educational homogamy in 65 countries: An explanation of differences in openness using country-level explanatory variables". American Sociological Review 63(2):264-285. doi: 10.2307/2657327

Soons, Judith P. M. and Kalmijn, Matthijs. (2009). "Is marriage more than cohabitation? Well-being differences in 30 European countries". Journal of Marriage and Family 71(5):1141-1157. doi:10.1111/j.1741-3737.2009.00660.x

Stevenson, Betsey and Wolfers, Justin. (2008). Marriage and the market. Cato Unbound. Cato Insitute. http://www.cato-unbound.org/2008/01/18/betsey-stevenson-justinwolfers/marriage-market [last accessed 02/11/2016]

Thomas, Claudia, Benzeval, Michaela, and Stansfeld, Stephen A. (2005). "Employment transitions and mental health: An analysis from the British household panel survey". Journal of Epidemiologcy and Community Health 59(3):243-249. doi: 10.1136/jech.2004.019778

Tzeng, Meei-Shenn. (1992). "The effects of socioeconomic heterogamy and changes on marital dissolution for first marriages". Journal of Marriage and Family 54(3):609619.

University of Essex. (2012). Institute for social and economic research and national centre for social research, Understanding Society: Waves 1-2, 2009-2011 [computer file]. 4th Edition. Colchester, Essex: UK Data Archive [distributor]. SN: 6614.

Verbakel, Ellen. (2012). "Subjective well-being by partnership status and its dependence on the normative climate". European Journal of Population 28(2):205-232. doi: 0.1007/s10680-012-9257-2

Wilson, Sven E. and Waddoups, Shawn L. (2002). "Good marriages gone bad: Health mismatches as a cause of later-life marital dissolution". Population Research And Policy Review 21(6):505-533. doi: 10.1023/A:1022990517611

Zellner, Arnold. (1962). "An efficient method of estimating seemingly unrelated regressions and tests for aggregation bias". Journal of the American Statistical Association 57(298):348-368. doi: 10.1080/01621459.1962.10480664

Zhang, Yuanting and Van Hook, Jennifer. (2009). "Marital dissolution among interracial couples". Journal of Marriage and Family 71(1):95-107. doi: 10.1111/j.17413737.2008.00582.x 


\section{APPENDIX 1}

Table A1. Number of couples by husband's (in rows) and wife's (in columns) characteristics

\begin{tabular}{|c|c|c|c|c|c|c|c|}
\hline Age & & & & & & & \\
\hline $6-25$ years younger & 109 & & & & & & \\
\hline $2-5$ years younger & 238 & & & & & & \\
\hline 1 year younger to 3 years older & 1,181 & & & & & & \\
\hline 4-9 years older & 622 & & & & & & \\
\hline $10+$ years older & 187 & & & & & & \\
\hline Total & 2,337 & & & & & & \\
\hline Father's class & $(1)$ & (2) & (3) & (4) & $(5)$ & (6) & Total \\
\hline (1) Managerial and professional occ. & 257 & 73 & 71 & 59 & 114 & 79 & 653 \\
\hline (2) Intermediate occ. & 54 & 27 & 37 & 27 & 39 & 31 & 215 \\
\hline (3) Small employers and own account workers & 97 & 28 & 57 & 31 & 62 & 51 & 326 \\
\hline (4) Lower supervisory and technical occ. & 71 & 21 & 33 & 35 & 57 & 40 & 257 \\
\hline (5) Semi-routine and routine occ. & 123 & 39 & 59 & 47 & 136 & 86 & 490 \\
\hline (6) Missing & 99 & 26 & 58 & 32 & 89 & 92 & 396 \\
\hline Total & 701 & 214 & 315 & 231 & 497 & 379 & 2,337 \\
\hline Education & (1) & (2) & (3) & (4) & Total & & \\
\hline (1) Degree & 534 & 160 & 53 & 22 & 769 & & \\
\hline (2) A-level or equivalent & 256 & 352 & 182 & 42 & 832 & & \\
\hline (3) GCSE or equivalent & 97 & 167 & 181 & 47 & 492 & & \\
\hline (4) No qualifications & 22 & 79 & 83 & 60 & 244 & & \\
\hline Total & 909 & 758 & 499 & 171 & 2,337 & & \\
\hline Ethnicity & (1) & (2) & (3) & Total & & & \\
\hline (1) White British & 1,654 & 41 & 12 & 1,707 & & & \\
\hline (2) Asian & 22 & 187 & 2 & 211 & & & \\
\hline (3) Black & 15 & 2 & 61 & 78 & & & \\
\hline Total & 1,691 & 230 & 75 & 1,996 & & & \\
\hline Religiosity & $(1)$ & (2) & (3) & Total & & & \\
\hline (1) No religious socialization & 258 & 170 & 163 & 591 & & & \\
\hline (2) Religious socialization, not religious anymore & 190 & 329 & 240 & 759 & & & \\
\hline (3) Religious socialization, still religious & 99 & 157 & 689 & 945 & & & \\
\hline Total & 547 & 656 & 1,092 & 2,295 & & & \\
\hline Native language & $(1)$ & $(2)$ & Total & & & & \\
\hline (1) Other & 225 & 63 & 288 & & & & \\
\hline (2) English & 136 & 1,913 & 2,049 & & & & \\
\hline Total & 361 & 1,976 & 2,337 & & & & \\
\hline Parental divorce & (1) & (2) & Total & & & & \\
\hline (1) Parental divorce before age 16 & 1,569 & 314 & 1,883 & & & & \\
\hline (2) No parental divorce before age 16 & 288 & 106 & 394 & & & & \\
\hline Total & 1,857 & 420 & 2,277 & & & & \\
\hline \multicolumn{8}{|l|}{ Number of similar characteristics } \\
\hline 0 & 7 & & & & & & \\
\hline 1 & 36 & & & & & & \\
\hline 2 & 145 & & & & & & \\
\hline 3 & 450 & & & & & & \\
\hline 4 & 702 & & & & & & \\
\hline 5 & 628 & & & & & & \\
\hline 6 & 308 & & & & & & \\
\hline 7 & 61 & & & & & & \\
\hline Total & 2,337 & & & & & & \\
\hline
\end{tabular}




\section{APPENDIX $2 \quad$ Descriptive results}

For descriptive purposes, we computed the adjusted mean well-being for each combination of the husband's and wife's score on a particular characteristic. We specified separate OLS regression equations for men and women in a seemingly unrelated regression model. These regressions were run separately for each characteristic and for each of the three outcomes and include the control variables. Results are presented in Tables A2 through A8. According to the similarity hypothesis, we should observe higher levels of well-being on the diagonals of these tables (where we find the couples with similar characteristics).

Table A2. Adjusted means of well-being variables by age-differences for men and women

\begin{tabular}{|c|c|c|c|c|c|c|c|c|}
\hline \multirow[b]{2}{*}{ Age difference; Husband is... } & \multicolumn{4}{|c|}{ Men } & \multicolumn{4}{|c|}{ Women } \\
\hline & $\begin{array}{l}\text { Rel.ship } \\
\text { quality }\end{array}$ & $\begin{array}{c}\text { Life } \\
\text { satisfaction }\end{array}$ & & $\begin{array}{l}\text { Psych. } \\
\text { distress }\end{array}$ & $\begin{array}{l}\text { Rel.ship } \\
\text { quality }\end{array}$ & $\begin{array}{c}\text { Life } \\
\text { satisfaction }\end{array}$ & $\begin{array}{l}\text { Psych. } \\
\text { distress }\end{array}$ & \\
\hline $6-25$ years younger & 4.91 & 5.27 & & 11.25 & 4.86 & 5.33 & 12.76 & $*$ \\
\hline $2-5$ years younger & 4.92 & 5.27 & & 10.35 & 4.86 & 5.44 & 11.45 & \\
\hline 1 year younger to 3 years older (ref) & 4.88 & 5.26 & & 10.42 & 4.88 & 5.42 & 11.02 & \\
\hline 4-9 years older & 4.85 & 5.24 & & 10.47 & 4.82 & 5.38 & 10.88 & \\
\hline $10+$ years older & 4.81 & 5.04 & $*$ & 10.70 & 4.88 & 5.36 & 10.67 & \\
\hline
\end{tabular}

* denotes significant difference (at $p<0.05)$ from the reference category. 
Table A3. Adjusted means of well-being variables by own and partner's social origin, for men and women

\section{Own father's class}

\section{Relationship quality}

(1) Managerial and professional occ.

(2) Intermediate occ.

(3) Small employers and own account workers

(4) Lower supervisory and technical occ.

(5) Semi-routine and routine occ.

(6) Missing

\section{Life satisfaction}

(1) Managerial and professional occ.

(2) Intermediate occ

(3) Small employers and own account workers

(4) Lower supervisory and technical occ.

(5) Semi-routine and routine occ.

(6) Missing

\section{Psychological distress}

(1) Managerial and professional occ.

(2) Intermediate occ.

(3) Small employers and own account workers

(4) Lower supervisory and technical occ.

(5) Semi-routine and routine occ.

(6) Missing

denotes significant differ

\section{Women}

Partner's father's class

\begin{tabular}{|c|c|c|c|c|c|c|c|c|c|c|c|c|c|c|c|c|c|c|}
\hline (1) & & (2) & & (3) & & (4) & & (5) & & (6) & & (1) & (2) & (3) & & (4) & 5 & 6 \\
\hline 4.90 & & 4.94 & & 4.87 & & 4.93 & & 4.95 & $\dagger$ & 4.82 & & 4.87 & 4.95 & 4.96 & & 4.94 & 4.90 & 4.90 \\
\hline 5.00 & & 4.92 & & 4.88 & & 4.96 & & 4.73 & & 4.86 & & 4.94 & 4.80 & 4.86 & & 4.99 & 4.82 & 4.92 \\
\hline 4.94 & & 4.81 & & 5.01 & & 5.03 & & 4.97 & & 4.76 & $*$ & 4.84 & 4.83 & 4.81 & & 4.70 & 4.82 & 4.87 \\
\hline 4.85 & & 5.26 & $*$ & 4.64 & $\dagger^{*}$ & 5.00 & & 4.88 & & 4.83 & & 4.87 & 4.99 & 5.10 & $\dagger$ & 4.89 & 4.94 & 4.82 \\
\hline 4.95 & $*$ & 4.97 & & 4.86 & & 5.01 & $*$ & 4.78 & & 4.70 & & 4.87 & 4.80 & 4.91 & & 4.80 & 4.84 & 4.91 \\
\hline 4.82 & & 4.85 & & 4.75 & $\dagger$ & 4.71 & & 4.84 & & 4.73 & & 4.83 & 4.84 & 4.69 & & 4.85 & 4.66 & 4.73 \\
\hline
\end{tabular}

4.82

\begin{tabular}{llllllllllllllll}
5.23 & 5.56 & 5.26 & 5.11 & 5.38 & 5.15 & 5.48 & 5.42 & 5.33 & $\dagger$ & 5.45 & 5.63 & 5.46 & $\dagger$ \\
5.05 & 5.33 & 5.28 & 5.75 & 4.96 & 5.51 & 5.57 & 5.40 & 5.50 & $\dagger$ & 5.34 & 5.54 & 5.39 & & \\
5.12 & 5.43 & 5.05 & 5.37 & 5.33 & 5.24 & 5.55 & $*$ & 5.49 & $*$ & 4.93 & 5.37 & 5.29 & 5.42 & $* \dagger$ \\
5.22 & 5.47 & 5.36 & 5.18 & 5.17 & 5.50 & 5.41 & 5.78 & 5.59 & $\dagger$ & 5.39 & 5.13 & 5.64 & $\dagger$ \\
5.41 & 5.06 & 5.14 & 5.41 & 5.19 & 5.25 & 5.38 & 5.10 & 5.31 & 5.51 & 5.40 \\
5.12 & 4.85 & 5.24 & 5.58 & 4.99 & 5.17 & 5.39 & $*$ & 5.21 & 5.25 & 5.44 & $*$ & 5.56 & $*$ & 4.89 & $\dagger$ \\
\hline
\end{tabular}

\begin{tabular}{|c|c|c|c|c|c|c|c|c|c|c|c|c|c|c|c|}
\hline 10.61 & 9.97 & 10.86 & 10.47 & 10.16 & 10.99 & 10.90 & & 11.31 & & 11.29 & 10.95 & & 10.26 & 10.98 & $\dagger$ \\
\hline 10.85 & 10.57 & 11.34 & 8.65 & 10.64 & 10.61 & 10.39 & & 12.25 & & 10.75 & 10.68 & & 10.51 & 10.07 & $\dagger$ \\
\hline 10.97 & 9.18 & 10.15 & 9.49 & 9.59 & 10.25 & 10.19 & $*$ & 10.73 & & 11.90 & 10.82 & & 10.73 & 10.83 & $\dagger$ \\
\hline 10.24 & 11.66 & 9.81 & 9.61 & 10.50 & 9.90 & 10.28 & & 9.11 & $\dagger$ & 10.35 & 9.99 & & 11.95 & 11.04 & \\
\hline 10.23 & 10.96 & 10.20 & 10.53 & 10.92 & 9.87 & 10.96 & & 11.09 & & 12.00 & 11.13 & & 11.38 & 11.71 & \\
\hline 11.01 & 10.07 & 10.38 & 10.26 & 11.86 & 10.60 & 11.37 & & 11.67 & & 12.11 & 10.56 & $*$ & 11.90 & 12.44 & \\
\hline
\end{tabular}


Table A4. Adjusted means of well-being variables by own and partner's education, for men and women

\begin{tabular}{|c|c|c|c|c|c|c|c|c|c|c|c|c|c|c|c|c|}
\hline \multirow{3}{*}{ Own education } & \multicolumn{8}{|c|}{ Men } & \multicolumn{8}{|c|}{ Women } \\
\hline & \multicolumn{8}{|c|}{ Partner's education } & \multicolumn{8}{|c|}{ Partner's education } \\
\hline & (1) & & (2) & & (3) & & (4) & & (1) & & (2) & & (3) & & (4) & \\
\hline \multicolumn{17}{|l|}{ Relationship quality } \\
\hline (1) Degree & 4.92 & & 4.93 & & 4.88 & & 4.62 & $*$ & 4.91 & & 4.94 & & 4.81 & & 4.70 & \\
\hline (2) A-level or equivalent & 4.91 & & 4.87 & & 4.88 & & 4.83 & & 4.86 & & 4.93 & & 4.87 & & 4.93 & $\dagger$ \\
\hline (3) GCSE or equivalent & 4.90 & & 4.82 & & 4.81 & & 4.85 & $\dagger$ & 4.70 & $\dagger$ & 4.78 & $\dagger$ & 4.75 & & 4.75 & \\
\hline (4) No qualifications & 4.65 & $\dagger$ & 5.04 & * & 4.74 & & 4.60 & & 4.83 & & 4.84 & & 4.76 & & 4.68 & \\
\hline \multicolumn{17}{|l|}{ Life satisfaction } \\
\hline (1) Degree & 5.24 & & 5.34 & & 5.64 & $*$ & 4.93 & & 5.52 & & 5.56 & $\dagger$ & 5.50 & & 5.35 & $\dagger$ \\
\hline (2) A-level or equivalent & 5.24 & & 5.12 & & 5.09 & $\dagger$ & 5.38 & $\dagger$ & 5.53 & & 5.34 & & 5.35 & & 5.48 & $\dagger$ \\
\hline (3) GCSE or equivalent & 5.43 & & 5.14 & * & 5.48 & & 5.29 & & 5.56 & & 5.18 & & 5.33 & & 5.06 & \\
\hline (4) No qualifications & 5.00 & & 5.30 & & 5.32 & $*$ & 4.88 & & 5.35 & $*$ & 5.70 & $*$ & 5.20 & * & 4.67 & \\
\hline \multicolumn{17}{|l|}{ Psychological distress } \\
\hline (1) Degree & 10.51 & & 11.00 & & 10.20 & & 12.24 & & 10.61 & & 10.64 & & 10.84 & & 10.68 & \\
\hline (2) A-level or equivalent & 10.08 & & 10.37 & & 10.69 & & 10.64 & & 10.53 & & 11.39 & & 11.49 & & 10.87 & \\
\hline (3) GCSE or equivalent & 9.99 & & 10.71 & & 10.32 & & 10.18 & & 11.39 & & 11.77 & & 11.53 & & 12.23 & \\
\hline (4) No qualifications & 11.80 & & 9.97 & & 10.39 & & 11.49 & & 10.88 & & 9.51 & $*_{\dagger}$ & 11.48 & & 11.93 & \\
\hline
\end{tabular}

* denotes significant difference (at $p<0.05)$ from the shaded cell in the row, + denotes significant difference (at $p<0.05)$ from the shaded cell in the column.

Table A5. Adjusted means of well-being variables by own and partner's ethnicity, for men and women

\begin{tabular}{|c|c|c|c|c|c|c|c|c|c|c|c|}
\hline \multirow{3}{*}{ Own ethnicity } & \multicolumn{5}{|c|}{ Men } & \multicolumn{6}{|c|}{ Women } \\
\hline & \multicolumn{5}{|c|}{ Partner's ethnicity } & \multicolumn{6}{|c|}{ Partners ethnicity } \\
\hline & (1) & (2) & & (3) & & (1) & & (2) & & (3) & \\
\hline \multicolumn{12}{|c|}{ Relationship quality } \\
\hline (1) White British & 4.89 & 4.68 & $\dagger$ & 4.65 & & 4.87 & & 5.03 & & 5.03 & \\
\hline (2) Asian & 4.94 & 4.88 & & 4.34 & & 4.68 & & 4.81 & & 5.10 & \\
\hline (3) Black & 4.74 & 5.16 & & 4.95 & & 4.91 & & 4.85 & & 5.03 & \\
\hline \multicolumn{12}{|l|}{ Life satisfaction } \\
\hline (1) White British & 5.29 & 4.51 & $* \dagger$ & 5.41 & \multirow{3}{*}{$* \dagger$} & 5.45 & & 5.89 & \multirow[t]{2}{*}{$\dagger$} & 5.13 & \\
\hline (2) Asian & 4.83 & 5.24 & & 3.01 & & 4.97 & $\dagger$ & 5.16 & & 3.58 & \multirow[t]{2}{*}{$\dagger$} \\
\hline (3) Black & 5.27 & 5.55 & & 5.08 & & 5.36 & & 2.44 & $* \dagger$ & 5.37 & \\
\hline \multicolumn{12}{|c|}{ Psychological distress } \\
\hline (1) White British & 10.40 & 12.74 & \multirow[t]{3}{*}{$* \dagger$} & 10.64 & & 11.21 & & 9.87 & & 12.40 & $\dagger$ \\
\hline (2) Asian & 12.15 & 10.19 & & 14.96 & & 11.39 & & 11.00 & \multirow[b]{2}{*}{$*$} & 7.70 & \\
\hline (3) Black & 10.53 & 10.13 & & 9.20 & & 9.74 & & 17.69 & & 8.37 & \\
\hline
\end{tabular}

* denotes significant difference (at $p<0.05$ ) from the shaded cell in the row, + denotes significant difference (at $p<0.05)$ from the shaded cell in the column. 
Table A6. Adjusted means of well-being variables by own and partner's religiosity, for men and women

\begin{tabular}{|c|c|c|c|c|c|c|c|c|c|}
\hline \multirow{3}{*}{ Own religion } & \multicolumn{4}{|c|}{ Men } & \multicolumn{5}{|c|}{ Women } \\
\hline & \multicolumn{2}{|c|}{ Partner's religion } & \multicolumn{7}{|c|}{ Partner's religion } \\
\hline & (1) & (2) & (3) & & (1) & & (2) & (3) & \\
\hline \multicolumn{10}{|l|}{ Relationship quality } \\
\hline (1) No religious socialization & 4.89 & 4.84 & 4.81 & & 4.93 & & 4.88 & 4.75 & $*$ \\
\hline $\begin{array}{l}\text { (2) Religious socialization, not religious } \\
\text { anymore }\end{array}$ & 4.85 & 4.95 & 4.83 & $*$ & 4.81 & & 4.92 & 4.77 & $*$ \\
\hline (3) Religious socialization, still religious & 4.89 & 4.88 & 4.88 & & 4.75 & $* \dagger$ & 4.86 & 4.88 & \\
\hline \multicolumn{10}{|l|}{ Life satisfaction } \\
\hline (1) No religious socialization & 5.17 & 5.27 & 5.14 & & 5.38 & & 5.53 & 5.35 & \\
\hline $\begin{array}{l}\text { (2) Religious socialization, not religious } \\
\text { anymore }\end{array}$ & 5.15 & 5.26 & 5.26 & & 5.37 & & 5.43 & 5.48 & \\
\hline (3) Religious socialization, still religious & 5.24 & 5.28 & 5.27 & & 5.17 & $*$ & 5.30 & 5.43 & \\
\hline \multicolumn{10}{|l|}{ Psychological distress } \\
\hline (1) No religious socialization & 10.63 & 10.56 & 10.25 & & 11.42 & & 10.84 & 11.47 & \\
\hline $\begin{array}{l}\text { (2) Religious socialization, not religious } \\
\text { anymore }\end{array}$ & 11.03 & 10.57 & 10.27 & & 11.58 & & 11.51 & 11.06 & $\dagger$ \\
\hline (3) Religious socialization, still religious & 10.57 & 10.80 & 10.31 & & 11.60 & $*$ & 11.43 & 10.45 & \\
\hline
\end{tabular}

* denotes significant difference (at $p<0.05$ ) from the shaded cell in the row, + denotes significant difference (at $p<0.05)$ from the shaded cell in the column.

Table A7. Adjusted means of well-being variables by own and partner's native language, for men and women

\begin{tabular}{|c|c|c|c|c|c|c|c|}
\hline \multirow{3}{*}{ Own native language } & \multicolumn{3}{|c|}{ Men } & \multicolumn{3}{|c|}{ Women } & \\
\hline & \multicolumn{3}{|c|}{ Partner's native lang. } & \multicolumn{4}{|c|}{ Partner's native lang. } \\
\hline & (1) & & (2) & (1) & & (2) & \\
\hline \multicolumn{8}{|l|}{ Relationship quality } \\
\hline (1) Other & 4.86 & & 4.93 & 4.89 & & 4.80 & \\
\hline (2) English & 4.76 & $*$ & 4.88 & 4.69 & $* \dagger$ & 4.87 & \\
\hline \multicolumn{8}{|l|}{ Life satisfaction } \\
\hline (1) Other & 5.25 & & 5.16 & 5.43 & & 5.16 & $* \dagger$ \\
\hline (2) English & 4.82 & $* \dagger$ & 5.27 & 5.02 & $* \dagger$ & 5.42 & \\
\hline \multicolumn{8}{|l|}{ Psychological distress } \\
\hline (1) Other & 10.22 & & 10.25 & 9.74 & & 11.45 & $*$ \\
\hline (2) English & 11.16 & & 10.48 & 12.22 & $\dagger$ & 11.17 & \\
\hline
\end{tabular}

$*$ denotes significant difference (at $p<0.05)$ from the shaded cell in the row, + denotes significant difference $(a t p<0.05)$ from the shaded cell in the column. 
Table A8. Adjusted means of well-being variables by own and partner's parental divorce, for men and women

\begin{tabular}{|c|c|c|c|c|c|c|c|}
\hline \multirow{3}{*}{ Own parents } & \multicolumn{3}{|c|}{ Men } & \multicolumn{4}{|c|}{ Women } \\
\hline & \multicolumn{2}{|c|}{ Partner's parents } & & \multicolumn{4}{|c|}{ Partner's parents } \\
\hline & (1) & (2) & & (1) & & (2) & \\
\hline Relationship quality & & & & & & & \\
\hline (1) Parental divorce before age 16 & 4.88 & 4.85 & & 4.88 & & 4.83 & \\
\hline (2) No parental divorce before age 16 & 4.89 & 4.80 & & 4.80 & & 4.77 & \\
\hline Life satisfaction & & & & & & & \\
\hline (1) Parental divorce before age 16 & 5.27 & 5.23 & & 5.45 & & 5.29 & $*$ \\
\hline (2) No parental divorce before age 16 & 5.22 & 5.04 & & 5.30 & $\dagger$ & 5.15 & \\
\hline Psychological distress & & & & & & & \\
\hline (1) Parental divorce before age 16 & 10.38 & 10.43 & $\dagger$ & 10.79 & & 11.87 & * \\
\hline (2) No parental divorce before age 16 & 10.50 & 11.50 & & 11.59 & $\dagger$ & 11.47 & \\
\hline
\end{tabular}

* denotes significant difference (at $p<0.05)$ from the shaded cell in the row, + denotes significant difference $($ at $p<0.05)$ from the shaded cell in the column. 